\title{
CARACTERIZAÇÃO MORFOLÓGICA DE EMBRIÕES POR IMAGENS DE RAIOS X E RELAÇÃO COM A MASSA E A QUALIDADE FISIOLÓGICA DE SEMENTES DE TECOMA STANS L. JUSS. EX KUNTH (BIGNONIACEAE) ${ }^{1}$
}

\author{
FÁBIO SOCOLOWSKI²; SILVIO MOURE CICERO ${ }^{3}$
}

\begin{abstract}
RESUMO - As imagens obtidas pelos raios X vêm sendo utilizadas na análise da qualidade de sementes desde os anos $50 \mathrm{e}$, atualmente, vêm se destacando por ser um método rápido, de boa precisão e não destrutivo. Deste modo, o presente trabalho foi realizado com o objetivo de avaliar as características morfológicas dos embriões de sementes de Tecoma stans L. Juss. ex Kunth pertencentes a diferentes classes de massa através da análise de imagens obtidas pelo uso dos raios X, correlacionando-as com a germinação e morfologia das plântulas. Foram utilizadas sete classes de massa com trinta sementes em cada classe, que foram submetidas aos raios X para a obtenção das imagens dos embriões. Os embriões, de cada uma das classes, foram separados de acordo com suas características morfológicas em 4 categorias (embriões sem defeito, embriões com pequenos defeitos, embriões deformados e sementes sem embrião). As sementes das diferentes classes de massa foram colocadas para germinar (emissão da raiz primária) e após dez dias foi observado o número de plântulas normais em cada uma das categorias e classes de massa. A maioria das sementes das classes 1 e 2, mais leves, apresenta-se com embriões deformados ou sem embrião, enquanto que as de maior massa (classes 3 a 7) apresentam embriões sem defeitos, em sua maioria ou totalidade. Quase a totalidade das sementes com embriões sem defeito germina, porém, nem todas dão origem a plântulas normais.
\end{abstract}

Termos para indexação: germinação de sementes, massa da semente, análise de imagens

\author{
EMBRYO MORPHOLOGICAL CHARACTERIZATION BY X-RAY IMAGE AND RELATION \\ WITH MASS AND PHYSIOLOGICAL QUALITY OF SEEDS OF TECOMA STANS L. JUSS. EX \\ KUNTH (BIGNONIACEAE)
}

\begin{abstract}
The images obtained by X-ray have been used to analyze seed quality since the 1950s and recently have gained prominence because it is a fast, accurate and non-destructive method. Thus the objective of this study was to evaluate the morphological characteristics of the embryo structure of Tecoma stans L. Juss. ex Kunth seeds with different mass, making use of X-ray images and correlating these images with seed germination and seedling morphological aspects. To obtain embryo images, seven classes of seed mass were used with thirty seeds in each class that were X-rayed . The embryos of each class of seed mass were separated according to their morphological characteristics in four categories (embryos without defect, embryos with small defect, deformed
\end{abstract}

${ }^{1}$ Submetido em 29/02/2007 Aceito para a publicação em 03/08/2008. Parte da tese de doutorado do primeiro autor apresentada à UNESP. Apoio CNPq/ FAPESP. ${ }^{2}$ Ecólogo, Doutor em Ciências Biológicas - Biologia Vegetal,
UNESP, Rio Claro - SP, e-mail: fsocolowski@yahoo.com.br. ${ }^{3}$ Prof. Titular do Depto. de Produção Vegetal, ESALQ/USP, Caixa Postal 9, 13418-900, Piracicaba-SP, e-mail: smcicero@esalq.usp.br. 
embryos and seeds without embryo). The seeds were placed to germinate (radicle protrusion) and after ten days the normal seedling number was observed in each class of seed mass. Most of the seeds in the 1 st and $2^{\text {nd }}$ classes of seed mass, that were lighter, had seeds with embryo deformity or seeds without embryo. Almost all or all the seeds with the highest mass (classes $3^{\text {rd }}$ to $7^{\text {th }}$ ) had seeds with embryos without defect. Almost all the seeds with embryos without defect germinated, buts not all gave origin to normal seedlings.

Index terms: seed germination, seed mass, image analysis technique

\section{INTRODUÇÃO}

Tecoma stans L. Juss. ex Kunth é uma espécie arbustivoarbórea com sementes anemocóricas (Lorenzi, 2000; Lorenzi et al., 2003), provavelmente originária do México (Sandwith $\&$ Hunt, 1974), que ocorre naturalmente desde o Sudeste da Flórida e Sul do Texas nos Estados Unidos passando pela América Central até o Nordeste da Argentina (Gentry, 1992). Atualmente está adaptada e naturalizada em muitas partes da América Tropical onde é muito utilizada na ornamentação, em virtude de suas flores amarelas (Sandwith \& Hunt, 1974). No Brasil é utilizada na ornamentação de parques e considerada planta daninha de pastagem (Lorenzi, 2000; Lorenzi et al., 2003) de difícil controle (Passini \& Kranz, 1997).

Em geral, sementes maiores, produzidas por uma determinada espécie, possuem embriões bem formados e com maior quantidade de substâncias de reserva, sendo, consequentemente, as mais vigorosas (Carvalho \& Nakagawa, 2000). Esta maior quantidade de reserva aumenta a probabilidade de sucesso no estabelecimento das plântulas (Haig \& Westoby, 1991).

A massa das sementes é apontada como uma característica que favorece a germinação e o crescimento inicial de suas plântulas (Weis, 1982; Morse \& Schmitt, 1985; Soltani et al., 2002), fazendo com que as sementes maiores apresentem uma emergência de plântulas mais rápida e um maior tamanho inicial (Parker et al., 2006).

A rápidaidentificação de danos mecânicos e de infestações causadas por insetos, pode auxiliar na identificação de problemas que influenciam na qualidade física e fisiológica das sementes e que, conseqüentemente, se refletem nos índices de germinação (Tonetti et al., 2006).

$\mathrm{O}$ teste de raios $\mathrm{X}$ para avaliar a qualidade das sementes vem sendo utilizado desde as décadas de 50 (Simak \& Gustafsson, 1953) e de 70 com o trabalho de Kamra (1976), que empregou os raios $\mathrm{X}$ para determinar a qualidade de sementes de florestas tropicais quanto ao desenvolvimento dos embriões, danos por insetos, danos mecânicos e até mesmo doenças.

A análise de imagens obtidas pelo uso dos raios X para a determinação de danos em sementes destaca-se como uma eficiente ferramenta, pois se trata de um método de grande precisão, que permite imagens detalhadas das áreas danificadas, além de ser um método não destrutivo (Cicero et al., 1998).

Quando uma semente é exposta aos raios $\mathrm{X}$, a radiação absorvida pelos tecidos depende não só da espessura, densidade e composição destes tecidos, mas também do comprimento de onda da radiação (Bino et al., 1993). Nas radiografias, as áreas mais escuras são aquelas em que a radiação atravessou com mais facilidade e as mais claras, partes mais densas (Simak, 1991).

A utilização de raios $X$ na deteç̧ão de defeitos nas estruturas dos embriões de sementes de Tabebuia serratifolia Vahlnich. e Tabebuia impetiginosa (Martius Ex A.P. de Candolle) Standley apresentou-se eficiente, permitindo a detecção de anomalias que se refletiram na qualidade do lote de sementes (Oliveira et al., 2004). Do mesmo modo, Machado \& Cicero (2003) observaram a eficiência dos raios X na detecção de anomalias em sementes de Lithraea molleoides (Vell.) Engl., o que permitiu a melhora da qualidade do lote pelo descarte das sementes mal formadas.

Este estudo teve como objetivo avaliar as características morfológicas dos embriões de sementes de Tecoma stans, pertencentes a diferentes classes de massa, através da análise de imagens obtidas pelo uso dos raios $\mathrm{X}$, correlacionando-as com a germinação e ao aspecto morfológico das plântulas.

\section{MATERIAL E MÉTODOS}

Os experimentos foram conduzidos nos Laboratórios de Análise de Imagens e de Análise de Sementes do Departamento de Produção Vegetal, Escola Superior de Agricultura "Luiz de Queiroz", Universidade de São Paulo (Piracicaba), e no Laboratório de Fotomorfogênese de Plantas do Departamento 
de Botânica, Universidade Estadual Paulista (Rio Claro).

As sementes de Tecoma stans L. Juss. ex Kunth foram colhidas de 18 indivíduos localizados no Campus da UNESP de Rio Claro, em julho de 2003. Destes mesmos indivíduos também foram colhidos 35 frutos secos, porém com as valvas ainda fechadas, que foram colocados dentro de sacos de papel em uma sala com temperatura de ambiente não controlada até a abertura das valvas, para a determinação de dez classes de massa segundo Fowler et al. (1998), como observadas na tabela 1. Para isso, foram contadas e pesadas, em balança de precisão de 0,0001 g, todas as sementes contidas em cada fruto.

TABELA 1. Classe de massa, amplitude de classe (mg), número de sementes por classe e freqüência relativa das sementes $(\%)$ de Tecoma stans L. Juss. ex Kunth. UNESP, Rio Claro, SP, 2004.

\begin{tabular}{cccc}
\hline $\begin{array}{c}\text { Classe de } \\
\text { massa }\end{array}$ & $\begin{array}{c}\text { Amplitude } \\
\text { de classe }\end{array}$ & $\begin{array}{c}\text { Número de } \\
\text { sementes/ } \\
\text { classe }\end{array}$ & $\begin{array}{c}\text { Freqüência } \\
\text { relativa das } \\
\text { sementes }\end{array}$ \\
\hline 1 & $0,2-1,7$ & 89 & 4,34 \\
2 & $1,8-3,3$ & 178 & 8,69 \\
3 & $3,4-4,9$ & 117 & 5,71 \\
4 & $5,0-6,5$ & 297 & 14,49 \\
5 & $6,6-8,1$ & 337 & 16,45 \\
6 & $8,2-9,7$ & 439 & 21,43 \\
7 & $9,8-11,3$ & 376 & 18,35 \\
8 & $11,4-12,9$ & 172 & 8,39 \\
9 & $13,0-14,5$ & 43 & 2,10 \\
10 & $14,6-16,1$ & 1 & 0,05 \\
\hline
\end{tabular}

Após a determinação das classes de massa, novas sementes foram colhidas de frutos abertos, colocadas para secar a temperatura de ambiente não controlado e armazenadas em recipientes de vidro a $10^{\circ} \mathrm{C}$ até o início dos experimentos, 8 meses depois. Como a freqüência das sementes nas classes 8,9 e 10, observadas nos frutos fechados, foi baixa (Tabela 1), não foi possível coletar sementes destas classes para a avaliação dos testes programados para os experimentos. Assim, foram utilizadas somente as sementes das sete primeiras classes.

O teor de água de cada uma das sete classes de massa foi determinado pela metodologia descrita nas Regras para Análise de Sementes (Brasil, 1992), com vinte sementes de cada classe.

Para a definição dos tempos e intensidade de radiação que possibilitassem uma visualização nítida do embrião e caracterização precisa das estruturas internas das sementes foram testadas intensidades de radiação que variaram entre 10 e $25 \mathrm{kV}$ e tempos de exposição de 30 a 360 segundos.

Trinta sementes, previamente identificadas (numeradas) de cada uma das sete classes de massa, foram colocadas em células de uma placa de acrílico para a obtenção das radiografias. Foram utilizados filmes radiográficos (Kodak MIN-R 2000, tamanho 18 × $24 \mathrm{~cm}$ ) a uma distância de $40 \mathrm{~cm}$ da fonte de radiação, em um aparelho de raios $\mathrm{X}$ FAXITRON X-Ray (MX-20). Os filmes foram revelados em uma processadora automática Hope X-Ray (319 Micromax). Posteriormente, as imagens foram digitalizadas uma a uma por um scanner Umax (PowerLook 1100).

Dentro de cada classe de massa, as sementes foram classificadas de acordo com a anatomia interna do embrião: embrião sem defeito (ESD) - semente contendo o embrião codiforme e com os "lóbulos" bem desenvolvidos; embrião com pequenos defeitos (EPD) - embrião com formato um pouco irregular ou com seus lóbulos pouco desenvolvidos; embrião deformado (ED) - embrião atrofiado muitas vezes apresentando material pouco denso ou mesmo embrião com rachaduras; semente sem embrião (SSE) - aquela que apresenta um resquício embrionário, ou nem mesmo isso, em seu interior.

Para avaliar os possíveis efeitos dos danos ou defeitos observados através da análise das imagens, todas as sementes utilizadas nas radiografias foram colocadas para germinar em células de forma de gelo, forradas com papel de filtro adequadamente umedecidas com água destilada, dentro de bandejas tampadas com vidro transparente, numa sala climatizada a $25 \pm 2{ }^{\circ} \mathrm{C}$. O acompanhamento da germinação, dada com a emissão da raiz primária, foi diário. Após dez dias da semeadura, foi avaliada a formação de plântulas, categorizadas como; normais, anormais e sementes mortas, que em seguida foram fotografadas. Foram consideradas plântulas normais as que apresentaram cotilédones expandidos, verdes e sem manchas, além de raízes primárias e secundárias; plântulas anormais aquelas que não tinham seus cotilédones expandidos e nem mesmo raízes secundárias e sementes mortas àquelas que não germinaram.

\section{RESULTADOS E DISCUSSÃO}

O teor de água variou entre as diferentes classes de massa das sementes de Tecoma stans L. Juss. ex Kunth, tendo a 
classe 1 apresentado $9,1 \%$ de umidade e as demais $8,5 \%$, $8,1 \%, 7,7 \%, 7,1 \%, 6,9 \%$ e $7,0 \%$, respectivamente da classe 2 a 7. A melhor combinação de intensidade de radiação e tempo de exposição foi a de $10 \mathrm{kV}$ por 180 segundos, por permitir a nítida visualização das estruturas internas das sementes.

Pelo exame das imagens das sementes de Tecoma stans, foi observado que somente a classe 1 apresentou sementes sem embrião (SSE) (Tabela 2), como pode ser observado na radiografia de uma semente que possui apenas um resquício embrionário no interior de sua cavidade embrionária (Figura 1A), resultando em semente morta ao final do experimento de germinação (Figura 1B).

TABELA 2. Porcentagem de sementes de Tecoma stans L. Juss. ex Kunth em cada classe de massa, classificadas de acordo com a análise radiográfica: embriões sem defeito (ESD); embriões com pequenos defeitos (EPD); embriões deformados (ED) e sementes sem o embrião (SSE). UNESP, Rio Claro, SP, 2004.

\begin{tabular}{ccccc}
\hline $\begin{array}{c}\text { Classe de } \\
\text { massa }\end{array}$ & ESD & EPD & ED & SSE \\
\hline 1 & 0,00 & 0,00 & 63,33 & 36,67 \\
2 & 13,33 & 6,67 & 80,00 & 0,00 \\
3 & 63,34 & 16,67 & 13,33 & 0,00 \\
4 & 96,67 & 0,00 & 3,33 & 0,00 \\
5 & 100,00 & 0,00 & 0,00 & 0,00 \\
6 & 100,00 & 0,00 & 0,00 & 0,00 \\
7 & 100,00 & 0,00 & 0,00 & 0,00 \\
\hline
\end{tabular}

FIGURA 1. Semente de Tecoma stans sem embrião (A) e respectiva semente morta $(B)$ observada na classe 1. Cavidade embrionária (c.e.), resquício embrionário (r.e.) e semente morta (s.m.). ESALQ/USP, Piracicaba, SP, 2004.
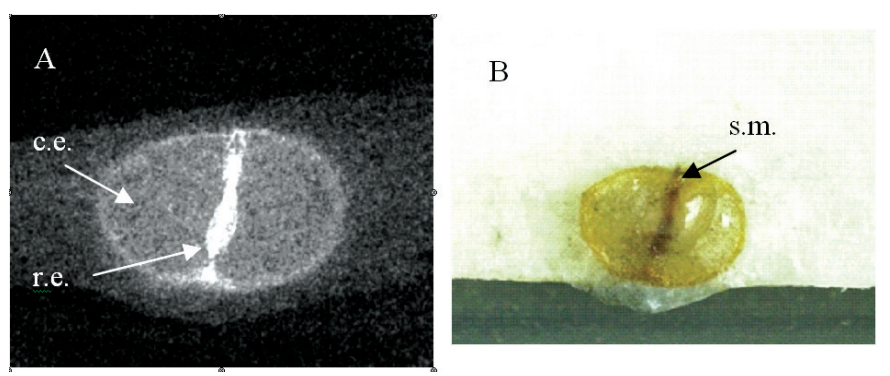

Sementes com embriões deformados (ED) foram mais comuns nas classes $1(63,33 \%)$ e $2(80 \%)$ (Tabela 2$)$. Na Figura $2 \mathrm{~A}$ pode ser observada a imagem radiográfica de uma semente da classe 1 com embrião defeituoso. Pode-se visualizar aí a formação de tecido embrionário membranáceo, sem um desenvolvimento pleno, visto como uma mancha mais clara no interior da cavidade embrionária, com a ponta da radícula de cor branca indicando maior densidade da massa neste local, resultando em semente morta no final do experimento de germinação (Figura 2B). Na Figura 3A observa-se um embrião deformado de uma semente da classe 2, com sua embriogênese incompleta, apresentando-se com formato irregular; além disso, pode ser observado pelas partes escuras na radiografia que o embrião possui tecidos com diferentes densidades, resultando no fim dos experimentos de germinação em semente morta (Figura 3B).

FIGURA 2.Semente de Tecoma stans com embrião deformado (A) e respectiva semente morta (B) observada na classe 1. Cavidade embrionária (c.e.), embrião deformado (e.d.), radícula (r.) e semente morta (s.m.). ESALQ/USP, Piracicaba, SP, 2004.

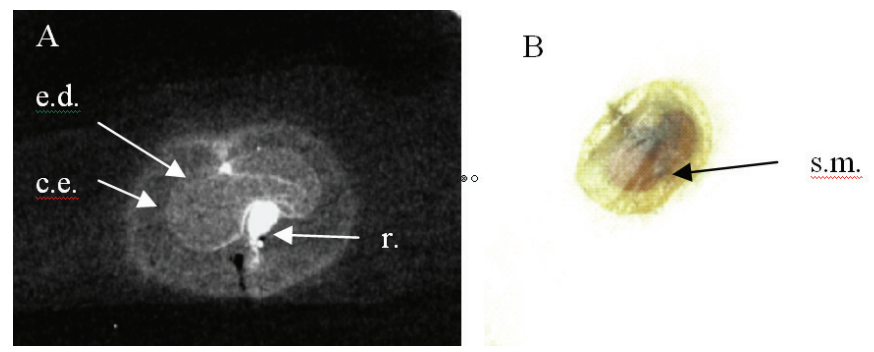

FIGURA 3.Semente de Tecoma stans com embrião deformado (A) e respectiva semente morta (B) observada na classe 2. Cavidade embrionária (c.e.), embrião deformado (e.d.) e semente morta (s.m.). ESALQ/USP, Piracicaba, SP, 2004.
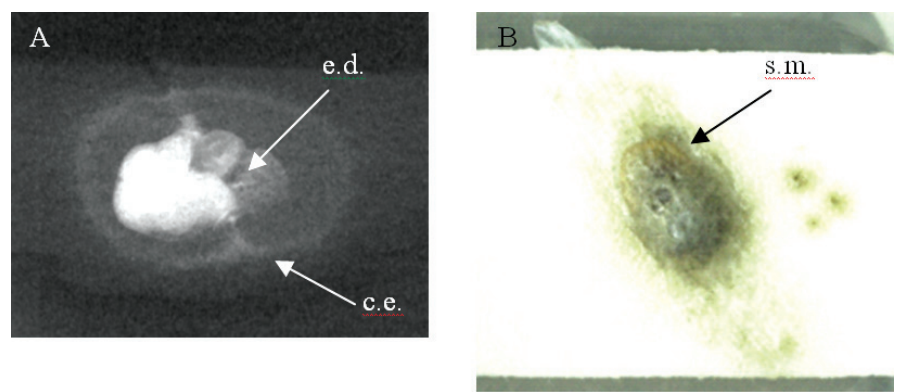
Por outro lado, as sementes com embriões deformados (ED) das classes $3(13,33 \%)$ e $4(3,33 \%)$ apresentaram embriões mais desenvolvidos do que os observados nas classes anteriores (Figura 4A) evidenciado pela germinação das sementes nestas classes (Tabela 3). Entretanto, nesta condição, as sementes que germinaram deram origem a plântulas anormais (Figura 4B). Diferentemente, em Tabebuia impetiginosa, Oliveira et al. (2004) observaram a formação de plântulas normais $(10 \%)$ oriundas de sementes deformadas.

FIGURA 4. Semente de Tecoma stans com embrião deformado (A) e respectiva plântula anormal (B) observada na classe 4 . Cavidade embrionária (c.e.), embrião deformado(e.d.), fissura (fi.), plântula anormal (p.a.) e raiz primária (r.p.). ESALQ/USP, Piracicaba, SP, 2004.
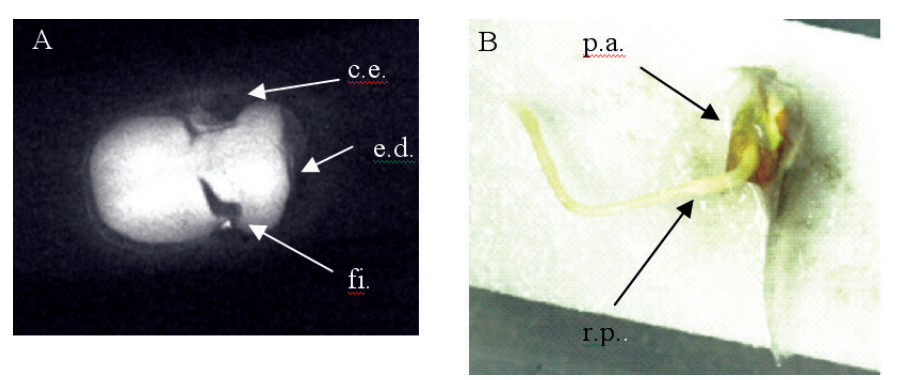

TABELA 3. Porcentagem de sementes de Tecoma stans $\mathbf{L}$. Juss. ex Kunth germinadas em cada classe de massa, classificadas de acordo com a análise radiográfica da morfologia dos embriões: embriões sem defeito (ESD); embriões com pequenos defeitos (EPD); embriões deformados (ED); sementes sem o embrião (SSE). UNESP, Rio Claro, SP, 2004.

\begin{tabular}{ccccc}
\hline $\begin{array}{c}\text { Classe de } \\
\text { massa }\end{array}$ & ESD & EPD & ED & SSE \\
\hline 1 & - & - & 0,00 & 0,00 \\
2 & 100,00 & 50,00 & 0,00 & - \\
3 & 100,00 & 80,00 & 25,00 & - \\
4 & 96,55 & - & 100,00 & - \\
5 & 100,00 & - & - & - \\
6 & 100,00 & - & - & - \\
7 & 100,00 & - & - & - \\
\hline
\end{tabular}

Embriões com pequenos defeitos (EPD) foram observados somente nas sementes das classes 2 e 3 , sendo mais freqüentes nesta última (Tabela 2). Alguns embriões desta categoria de desenvolvimento apresentaram a emissão da raiz primária (Tabela 3). Porém, nas sementes da classe 2, 50\% delas deram origem a plântulas anormais e 50\% a sementes mortas. Já na classe 3, 80\% deram origem a plântulas anormais e os $20 \%$ restantes a sementes mortas (Tabela 4). Na Figura 5A pode-se observar uma semente da classe 2 com embrião com pequeno defeito (EPD) no que diz respeito ao desenvolvimento dos lóbulos de seus cotilédones e pela saliência da radícula; nesta situação a germinação da semente deu origem a uma plântula anormal (Figura 5B). Na Figura 6A observa-se que o embrião não apresentou simetria no desenvolvimento dos lóbulos dos cotilédones, resultando, também, em plântula anormal (Figura 6B).

FIGURA 5 . Semente de Tecoma stans com embrião com pequeno defeito (A) e respectiva plântula anormal (B) observada na classe 2. Cavidade embrionária (c.e.), embrião com pequeno defeito (e.p.d.), plântula anormal (p.a.), radícula (r.) e raiz primária (r.p.). ESALQ/ USP, Piracicaba, SP, 2004.
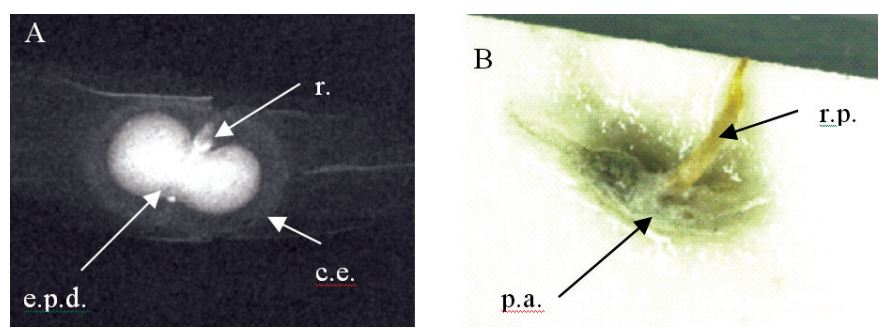

FIGURA 6. Semente de Tecoma stans com embrião com pequeno defeito $(\mathrm{A})$ e respectiva plântula anormal (B) observada na classe 3. Cavidade embrionária (c.e.), embrião com pequeno defeito (e.p.d.), raiz primária (r.p.) e plântula anormal (p.a.). ESALQ/USP, Piracicaba, SP, 2004.
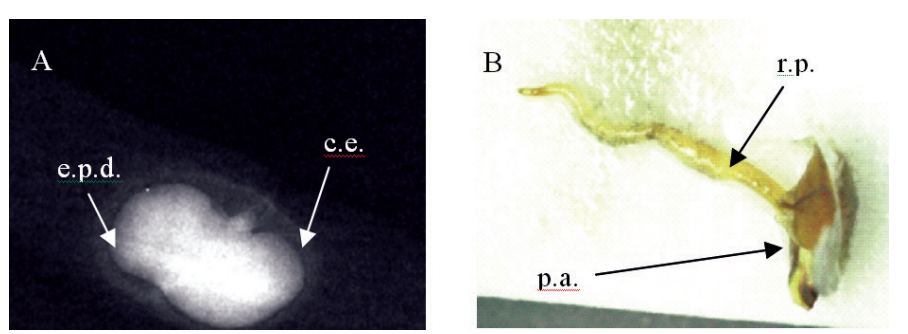
TABELA 4 .Porcentagem de plântulas normais, de plântulas anormais e de sementes mortas provenientes de sementes de Tecoma stans L. Juss. ex Kunth, em cada classe de massa, de acordo com as características de seus embriões: embriões sem defeito (ESD); embriões com pequenos defeitos (EPD); embriões deformados (ED); sementes sem o embrião (SSE). UNESP, Rio Claro, SP, 2004.

\begin{tabular}{|c|c|c|c|c|}
\hline Classe de massa & Características dos embriões & Plântula normal & Plântula anormal & Semente morta \\
\hline & & --------------- & - $\%$ & ------------------ \\
\hline \multirow{4}{*}{1} & ESD & - & - & - \\
\hline & EPD & - & - & - \\
\hline & ED & 0,00 & 0,00 & 100,00 \\
\hline & SSE & 0,00 & 0,00 & 100,00 \\
\hline \multirow{4}{*}{2} & ESD & 100,00 & 0,00 & 0,00 \\
\hline & EPD & 0,00 & 50,00 & 50,00 \\
\hline & ED & 0,00 & 0,00 & 100,00 \\
\hline & SSE & - & - & - \\
\hline \multirow{4}{*}{3} & ESD & 90,47 & 9,53 & 0,00 \\
\hline & EPD & 0,00 & 80,00 & 20,00 \\
\hline & ED & 0,00 & 0,00 & 100,00 \\
\hline & SSE & - & - & - \\
\hline \multirow{4}{*}{4} & ESD & 75,86 & 24,14 & 0,00 \\
\hline & EPD & - & - & - \\
\hline & ED & 0,00 & 100,00 & 0,00 \\
\hline & SSE & - & - & - \\
\hline \multirow{4}{*}{5} & ESD & 73,33 & 26,67 & 0,00 \\
\hline & EPD & - & - & - \\
\hline & ED & - & - & - \\
\hline & SSE & - & - & - \\
\hline \multirow{4}{*}{6} & ESD & 86,67 & 13,33 & 0,00 \\
\hline & EPD & - & - & - \\
\hline & ED & - & - & - \\
\hline & SSE & - & - & - \\
\hline \multirow{4}{*}{7} & ESD & 76,67 & 23,33 & 0,00 \\
\hline & EPD & - & - & - \\
\hline & ED & - & - & - \\
\hline & SSE & - & - & - \\
\hline
\end{tabular}


A maioria das sementes da categoria de embriões sem defeitos (ESD) foi observada nas classes $4(96,67 \%), 5$ $(100 \%), 6(100 \%)$ e $7(100 \%)$ (Tabela 2$)$, indicando que quanto mais pesadas as sementes, maior foi o desenvolvimento do embrião. Na Tabela 3 observa-se que todas as sementes que apresentaram embriões sem defeito germinaram (100\%), com exceção da classe $4(96,55 \%)$. Todas as sementes da classe 2, desta categoria, deram origem a plântulas normais. Porém, nem todas as sementes com embriões sem defeito da classe 3 deram origem a plântulas normais (Tabela 4). A classe 4 apresentou 96,67\% dos embriões sem defeito (Tabela 2), sendo que $75,86 \%$ destes deram origem a plântulas normais e o restante originando plântulas anormais (Tabela 4). Exemplo do desenvolvimento desses embriões pode ser observado na figura 7A, que nesta condição resultou em plântula normal (Figura 7B). Observa-se que a massa das sementes é um importante indicador de sua qualidade fisiológica e que a retirada das sementes pertencentes às classes 1, 2 e 3 melhoraria consideravelmente a formação de plântulas normais. Porém, imagens de raios X são importantes para a observação da qualidade física das sementes, como observado nas imagens de sementes de Eugenia pleurantha O. Berg (Masetto et al., 2007).

FIGURA 7. Semente de Tecoma stans com embrião sem defeito (A) e respectiva plântula normal (B) observada na classe 6. Cavidade embrionária (c.e.), embrião sem defeito (e.s.d.), cotilédone (cot.) e raiz primária (r.p.). ESALQ/USP, Piracicaba, SP, 2004.

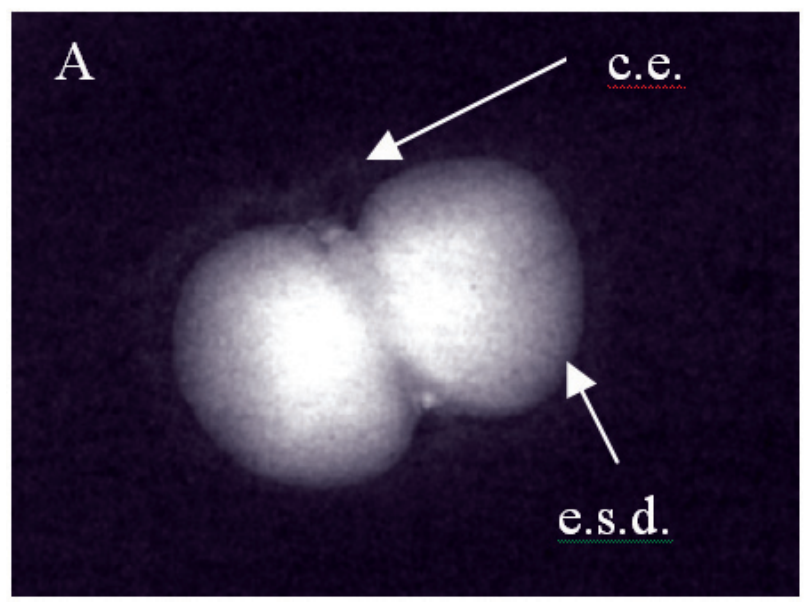

Sementes de Eremanthus erythropappus (DC.) Mac. Leish separadas nos teste de raios X em semente cheia, mal formada e vazia tiveram influência direta nos resultados de protrusão da raiz primária e formação de plântula normal, com as sementes mal formadas apresentando potencial germinativo reduzido quando comparados com as sementes cheias (Tonetti et al., 2006).

De acordo com Oliveira et al. (2003), a morfologia interna das sementes pode ser um indicativo do potencial de viabilidade. Entretanto, devido à variação natural, sementes que apresentam boas características visualizadas nas radiografias podem não germinar, provavelmente devido às infecções causadas por microrganismos ou por estarem mortas (Burg et al., 1994). Assim, as sementes que emitiram a raiz primária e não formaram plântulas normais poderiam estar em estádio inicial de perda de viabilidade.

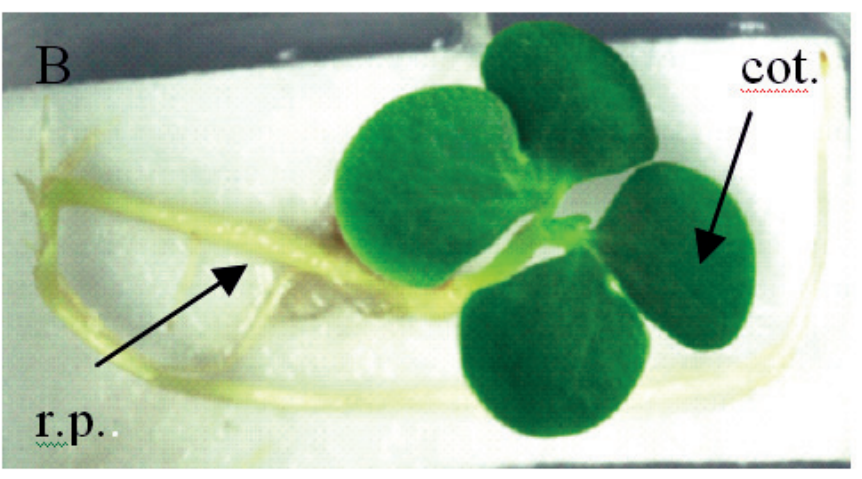

Neste contexto, fazer inferências a respeito da qualidade das sementes baseado somente no exame radiográfico pode ser questionável (Machado \& Cicero, 2003), necessitando, dessa maneira, de testes fisiológicos.

As imagens de raios $\mathrm{X}$ permitiram visualizar o grau de desenvolvimento dos embriões de Tecoma stans dentro de cada classe de massa das sementes, possibilitando observar anomalias embrionárias, características de determinadas classes de massa, que provavelmente tiveram origem durante a maturação dos frutos.

Também foi possível observar que a emissão da raiz primária ocorreu de maneira mais contundente do que a formação de plântulas normais, já que nem todas as sementes que emitiram a raiz primária originaram plântulas normais. Isso indica a maior eficiência da avaliação de toda a plântula em relação apenas à simples avaliação da protrusão da raiz 
primária.

\section{CONCLUSÕES}

A análise das imagens de raios $\mathrm{X}$ permite visualizar os processos de má formação dos embriões de acordo com as classes de massas das sementes e a identificação de danos internos nas sementes de Tecoma stans L. Juss. ex Kunth.

A capacidade germinativa das sementes de Tecoma stans L. Juss. ex Kunth é maior nas classes onde se verificam embriões mais desenvolvidos ou com pequenos danos, detectados pelas imagens de raios $\mathrm{X}$.

\section{REFERÊNCIAS}

BINO, R.J.; AARTSE, J.W.; BURG, W.J. van der. Nondestructive X-ray of Arabidopsis embryo mutants. Seed Science Research, Wallingford, v.3, n.2, p.167-170, 1993.

BRASIL. Ministério da Agricultura e Reforma Agrária. Regras para análise de sementes. Brasília, DF: SNDA/ DNDU/CLA, 1992. 365p.

BURG, W.J. van der; AARTSE, J.W.; VAN ZWOL, R.A.; JALINK, H.; BINO, R.J. Predicting tomato seedling morphology by X-ray analysis of seeds. Journal American Society for Horticultural Science, Virginia, v.119, n.2, p.258-263. 1994.

CARVALHO, N.M.; NAKAGAWA, J. Sementes: ciência tecnologia e produção. 4. ed. Jaboticabal: FUNEP, 2000. $588 \mathrm{p}$.

CICERO, S.M.; HEIJDEN, G.W.A.M. van der; BURG, W.J. van der; BINO, R.J. Evaluation of mechanical damages in seeds of maize (Zea mays L.) by X ray and digital imaging. Seed Science and Technology, Zürich, v.26, p.603-612, 1998.

FOWLER, J.; COHEN, L.; JARVIS, P. Practical statistics for field biology. Chichester: Jonh Wiley \& Sons Ltda, 1998. $254 p$.

GENTRY, A.H. Bignoniaceae. Flora Neotropica, New York, pt.2, p.84-287, 1992.

HAIG, D.; WESTOBY, M. Seed size, pollination costs and angiosperm success. Evolutionary Ecology, London, v.5, n.3, p.231-247, 1991 .

KAMRA, S.K. Use of X-ray radiography for studying seed quality in tropical forestry. Studia Forestalia Suecica,
Uppsala, n.131, p.1-34, 1976.

LORENZI, H. Plantas daninhas do Brasil: terrestres, aquáticas, parasitas e tóxicas. 3.ed. Nova Odessa: Plantarum, 2000. 608p.

LORENZI, H.; SOUZA, H.M.; TORRES, M.A.V.; BACHER, L.B. Árvores exóticas no Brasil: madeireiras, ornamentais e aromáticas. Nova Odessa: Plantarum, 2003. 368p.

MACHADO, C.F.; CICERO, S.M. "Aroeira-branca" [Lithraea molleoides (Vell.) Engl. - Anacardiaceae] seed quality evaluation by the X-ray test. Scientia Agricola, Piracicaba, v.60, n.2, p.393-397, 2003.

MASETTO, T.E.; DAVIDE, A.C.; SILVA, E.A.A.; FARIA, J.M.R. Avaliação da qualidade de sementes de Eugenia pleurantha (Mytaceae) pelo teste de raios X. Revista Brasileira de Sementes, Brasília, DF, v.29, n.3, p.170-174, 2007.

MORSE, D.H.; SCHMITT, J. Propagule size, dispersal ability, and seedling performance in Asclepias syriaca. Oecologia, Heidelberg, v.67, p.372-379, 1985.

OLIVEIRA, L.M.; CARVALHO, M.L.M.; DAVIDE, A.C. Utilização do teste de raios-X na avaliação da qualidade de sementes de Canafístula (Peltophorium dubium (Sprengel) Taubert. Revista Brasileira de Sementes, Brasília, DF, v.25, n.1, p.116-120, 2003.

OLIVEIRA, L.M.; CARVALHO, M.L.M.; GUIMARÃES, R.M.; MASETTO, T.E. Avaliação da qualidade de sementes de Tabebuia serratifolia Vahlnich. e T. impetiginosa (Martius Ex A.P. de Candolle) Standley - (Bignoniaceae) pelo teste de raios X. Revista Brasileira de Sementes, Brasília, DF, v.26, n.2, p.138-143, 2004.

PARKER, W.; NOLAND, T.L.; MORNEAULT, A.E. The effects of seed mass on germination, seedling emergence, and early seedling growth of eastern white pine (Pinus strobus L.). New Forests, v.32, p.33-49, 2006.

PASSINI, T., KRANZ, W. Eficácia de herbicidas no controle de amarelinho (Tecoma stans) em pastagem. Planta Daninha, Viçosa, v.15, p.190-197, 1997.

SANDWITH, N.Y.; HUNT, D.R. Bignoniaceas. Flora Ilustrada Catarinense, Itajaí, pt.1, p.15-20, 1974.

SIMAK, M. Testing of forest tree and shrub seeds by X-radiography. In: GORDON, A.G.; GOSLING, P.G.; WANG, B.S.P. (Ed.). Tree and shrub seed hand book. Zürich: ISTA, 1991.

SIMAK, M.; GUSTAFSSON, A. X-ray photography and sensitivity in forest tree species. Hereditas, v.39, p.458-468, 1953. 
SOLTANI, A.; GALESHI, S.; ZEINALI, E.; LATIFI, N. Germination, seed reserve utilization and seedling growth of chickpea as affected by salinity and seed size. Seed Science and Technology, Zürich, v.30, n.1, p.51-60, 2002.

TONETTI, O.A.O.; DAVIDE, A.C.; SILVA, E.A.A. Qualidade física e fisiológica de sementes de Eremanthus erythropappus (DC.) Mac. Leish. Revista Brasileira de Sementes, Brasília, DF, v.28, n.1, p.114-121, 2006.

WEIS, M. The effects of propagule size on germination and seedling growth in Mirabilis hirsuta. Canadian Journal of Botany, v.60, p.1868-1874, 1982. 